\title{
De "mortos-vivos" a "não-mortos": pensamento mágico, violência e insurgência nos protestos atuais
}

\section{From "living-dead" to "undead": magical thinking, violence and insurgency in the present protests}

\author{
Marília Etienne Arreguy ${ }^{1,2}$
}

\begin{abstract}
RESUMO
O presente ensaio parte da ideia de que certa juventude apolítica, os mortos-vivos alienados pelo consumo, tenham ressurgido das trevas como "não-mortos", indignados em movimentos sociais que se alastraram na última década como forma de reação à exploração e usurpação entranhada no Estado. Contudo, a violência objetiva do capital ainda permanece invisibilizada. Critica-se a "passagem ao ato violento" com base no "pensamento mágico" de que se possa derrubar o sistema com estratégias que não sejam coletivamente estruturadas. A juventude insurgente acaba sendo punida, tornando-se foco de repressão com base na criminalização da "violência subjetiva". Do movimento blackblock ao movimento de ocupação das escolas, os jovens indignados vêm construindo novas formas críticas de romper com a lógica punitiva a que estão submetidos.
\end{abstract}

Palavras-chave: pensamento mágico; insurgência; violência; mortos-vivos; alienação; psicanálise e política.

DOI: $10.1590 / 0104-4060.50025$

1 Universidade Federal Fluminense. Programa de Pós-Graduação em Educação. Niterói, Rio de Janeiro, Brasil. Rua Prof. Marcos Waldemar Freitas Reis, s/nº, Bloco D, sala 417. Gragoatá. CEP: 24210-201.E-mail: mariliaetienne@id.uff.br

2 Membro da Association Internationale des Interactions de la Psychanalyse - Paris. Agradeço a colaboração de Maria Luisa Bampi e David Miqueias, participantes do Grupo Alteridade Psicanálise e Educação - GAP(E), da Universidade Federal Fluminense e Conselho Nacional de Desenvolvimento Científico e Tecnológico $(\mathrm{CNPq})$ na discussão e construção deste texto. 


\begin{abstract}
This essay is based on the idea that a certain apolitical youth, the "livingdead" alienated by consumption, have risen from the darkness as "undead", outraged in social movements that have spread in the last decade as a reaction to the exploitation and usurpation entrenched in the State. However, the objective violence of capital still remains invisible. The "violent acting out" based on a "magical thinking" is criticized because it cannot overthrow the system with skills that are not collectively structured. The insurgent youth ends up being punished, becoming a focus of repression based on the criminalization of "subjective violence". From the blackblock movement to the occupation movement in schools, the indignant youths have been building new critical ways of breaking with the punitive logic to which they have been submitted.
\end{abstract}

Keywords: magical thinking; insurgency; violence; living-dead; alienation; psychoanalysis and politics.

\title{
Introdução
}

Pretendo discutir alguns aspectos psíquicos apresentados nas manifestações de revolta jovem e estudantil contemporâneas, com ênfase nas noções de "pensamento mágico" e de "mortos-vivos" advindas da estética dos quadrinhos e do cinema. A concepção de "mortos-vivos" aqui esboçada sustenta-se no enunciado usual de que os jovens das gerações pós-revolucionárias de 1980 e 1990 seriam “apolíticos", ou seja, nulos em matéria de política. Não só os jovens, mas a sociedade de um modo geral, seriam alienados pelo consumo, vivendo num modo hedonista, como aparece alegoricamente na apocalíptica saga Matrix (dir.: Irmãos Wachowski, 1999). A postura "apolítica" de certa "geração coca-cola", avessa em relação à política, seria parecida com a escolha daqueles que tomam a "pílula azul" no filme, de modo a não conhecer o mal que lhes acomete. Essa postura é predominante nos "mortos-vivos" brasileiros, ao afirmarem orgulhosamente que não se interessam, nem se envolvem com política.

Contrariando essa premissa, a reação de indignação ocorrida no mundo todo, desde a Primavera Árabe em 2011, até o movimento de ocupação de ruas, espaços públicos e escolas, surgiu com força de apropriação política da juventude brasileira. O ímpeto alimentado por inúmeras reivindicações trouxe novos ares ao debate público e, certamente, teve algum êxito, afinal, tirou mi- 
1hões de pessoas de um estado de letargia e nulidade política para uma posição de luta e resistência. Entretanto, a onda de manifestações ocorrida em 2013 envolvendo toda a população do país terminou por resvalar para o campo da violência reativa, supostamente justificável, mas em grande parte ineficaz. Os destinos das manifestações no Brasil e no mundo foram difusos e geraram novas formas de opressão.

Uma onda de atitudes ultraconservadoras surgiu como resposta ao mal-estar generalizado surgido em manifestações de origem popular. Blackblocs e mascarados orquestraram o desfecho de muitas manifestações de rua em episódios de violência insurgente. Pretendemos analisar, sob a lupa da psicanálise, essa contraviolência "jovem" em relação à violência instituída pelo Estado, enfocando as vicissitudes do "pensamento mágico" posto em ato na esfera coletiva. Pretendemos explorar a ideia de que tais atitudes representam a passagem de uma situação "apolítica" dos "mortos-vivos" (living dead), supostamente alienados sujeitos do consumo, a uma atitude política, porém caótica, dos "não-mortos" (undead ou "não mais mortos") ressurgidos das trevas da alienação para a participação política na esfera pública.

\section{A montagem perversa do capitalismo de consumo: avatares da alienação contemporânea}

Façamos uma digressão para definir as bases da alienação pelo consumo, fundamento para a constituição apolítica dos sujeitos que chamamos aqui de "mortos-vivos". Na linha do que define o filósofo Dany Robert Dufour, em seu livro $A$ cidade perversa, é necessário refletir sobre a preconização de um tipo específico de adicção que impele o sujeito a toda forma de apego ao fetiche e à pornografia, tornando o motus do consumo extremamente erotizado e acrítico.

Dufour (2009/2013) demonstra como a montagem capitalista explora a subjetividade atrelando-a essencialmente ao desejo de consumir objetos com vistas a extrair o potencial financeiro e dominar as massas. Esse processo surgiu desde a fundação do liberalismo por Adam Smith (1723-1790), combinando suas injunções ao elogio à perversão feito pelo Marquês de Sade (1740-1814). Para Dufour, sadismo e liberalismo seriam, conjuntamente, os principais pilares do capitalismo moderno, na medida em que ambos incitam, respectivamente, ao gozo ilimitado e à voracidade em relação ao consumo. O auge dessa combinatória acontece na virada do capitalismo de produção para o capitalismo de 
consumo com o crash da bolsa de Nova Iorque, em $1929^{3}$. Para sair da crise, era necessário enredar a todos na trama do consumo e da produção. Às mulheres, a entrada no mercado de trabalho potencializou sua capacidade de consumo; aos homens, caberia a incitação à fixação pela figura da mulher fetichizada... O ícone desses excessos seria a figura da pin up, ao mesmo tempo representando o objeto primordial a ser consumido, a sexualidade feminina e, de modo contíguo, o mais novo consumidor, a mulher que passou também a consumir bens, alavancando a economia.

A figura d'A mulher não castrada (LACAN, 1972-1973) que fuma, excita, produz e consome, seduz de modo ostensivo a todos, na medida em que fisga a sexualidade "perverso-polimorfa", tornando a subjetividade refém das pulsões parciais. (FREUD, 1905/1996). Assim, os objetos de consumo mais variados, do salto ao cigarro, foram associados à figura da mulher como fetiches a serem comprados e cultivados, de modo a driblar a castração coletiva. O ícone da pin up explorado pelo marketing alimenta um modo de alienação social que se funda na colocação do fetiche no centro de interesse psíquico das massas, incitando inclusive ao gozo pela pornografia. O corpo feminino e a sexualidade entram em cena como objetos por excelência a serem consumidos. Trata-se do uso dos prazeres com foco no desvio do interesse acerca da história, pela incitação ao gozo ilimitado voltado para a comercialização de objetos, à manipulação dos afetos e ao apagamento da consciência da divisão de classes.

A centralidade da figura da pin up no jogo capitalista evoca, dessa forma, uma apologia ao fantasma d'A mulher não castrada, o ser supremo que tudo pode e tudo tem. Esse seria o modelo a que todos estariam submetidos. O elogio hedonista ao consumo se sustenta na identificação com esse ícone de realização erótica cujo gozo tirânico, supostamente, qualquer sujeito seria capaz de alcançar. A tirania do consumo promove assim uma fantasia de exceção à incontornável renúncia pulsional. (FREUD, 1929/1996). Essa forma de gozo também pode ser exemplificada atualmente com a simulação dos videogames, em que muitos jovens se lançam na pele de heróis e anti-heróis sanguinários que matam em larga escala, mas cuja realização se baseia num gozo predominantemente imaginário. Em suma, a lógica perversa inerente ao capitalismo tardio se baseia, em grande parte, na exploração da fantasia subjetiva através de propagandas que prometem acesso a um gozo fácil, evidentemente, sem alertar que o produto

3 Subsequentemente, como sabemos, formou-se a base para o atual capitalismo financeiro virtual globalizado, cuja dimensão exploratória se funda em pilares profundamente segregadores, construídos pela política dos "masters of mankind", os autointitulados "mestres da humanidade", como atesta o documentário recém-publicado, baseado em estudos de Noam Chomsky: Requiem for the American Dream. Disponível em: <https://www.youtube.com/watch?v=T-2WE_51CsM>. Acesso em: 18 dez. 2016. 
vendido jamais pode conter a promessa, como a cenoura amarrada na frente do burro para fazê-lo andar sem parar... Nesse contexto, a existência hedonista e individualista aplaina em grande parte a possibilidade de eclosão do exercício político, aplacando concepções de vida pautadas por princípios éticos.

A manipulação do desejo das massas se deu através do desenvolvimento das Relações Públicas no Estados Unidos ao longo do século XX, conforme descrito no documentário produzido pela $\mathrm{BBC}$ de Londres: $O$ século do ego ${ }^{4}$. O documentário exalta o uso distorcido da psicanálise no advento do marketing, mas ignora a importância da influência behaviorista nesse escopo. A propaganda, de algum modo erotizada, passou então a ser a forma mais efetiva de produção da alienação seja pela idolatria à estética, seja pelo direcionamento da libido à lógica do consumo incessante de bens e de pornografia, seja pela condução tendenciosa de eleições. O centro de comando dos mestres da humanidade evidencia, portanto, uma violência objetiva (ŽIŽEK, 2008) subjacente ao sistema capitalista em si mesmo, que prega um modo de ser e viver inatingível para a grande maioria da população mundial.

Assim, a aliciação e o apego ao consumo total representariam a submissão a uma forma sutil de violência dissimulada em forma de fantasias prontas, impingidas pelo grande Outro mercadológico. Essa é uma das principais características da violência do Estado atrelado ao mercado na perspectiva neoliberal. Enfatiza-se a sedução pelo marketing, geradora de enganação e frustração para a grande maioria, destinada ao consumo falho. Se por ventura essa forma de dominação pelo desejo falhar, cabe ao Estado a função de "defender a sociedade" (FOUCAULT, 1975-1976/2000) de toda forma de insurgência, na medida em que se controla, espanca e prende sujeitos, quando as massas se rebelam e vão às ruas. Manifestantes que atacam concretamente as insígnias do poder são alvo de violência pela instauração de um estado de medo, de modo a reprimir a crítica contra o sistema. A mídia de massa, atrelada aos interesses de oligarquias econômicas, por sua vez, reduz o foco de divulgação e interpretação das manifestações para que se perceba apenas essas formas visíveis de violência, ou seja, aquela cometida por um sujeito ou um grupo isolado de sujeitos contra o sistema. Assim, a percepção da violência sistêmica que funda as sociedades capitalísticas fica camuflada diante de episódios de explosão de rebeldia insurgente.

Remontando às vastas manifestações de indignação política ocorridas no Brasil em junho de 2013, constata-se que havia uma diversidade de interesses motivadores da indignação massificada. Diversos sujeitos e grupos não apresentavam qualquer relação com uma causa ideológica unificada. Ao passo que

4 Dirigido por Adam Curtis em 2002. Disponível em: $<$ http://www.nicholasgimenes.com. br/2012/02/o-seculo-do-ego-century-of-self-bbc.html>. Acesso em: 19 dez. 2016. 
o início das manifestações aparentava um revival revolucionário com uma pauta popular expressiva contra o aumento das tarifas de ônibus, representando um despertar da juventude outrora "apolítica", ao fim das manifestações boa parte do povo parecia apenas movida pela raiva turbinada inconscientemente pela passagem ao ato coletivo, e por uma incontestável divergência de opiniões e interesses de classe. O documentário Junho (dir. João Wainer, 2014) traz inúmeros depoimentos a esse respeito. Indagamos, então, quais os destinos desse ressurgimento de uma juventude afeita à reivindicação política?

\section{A inversão midiática da lógica da violência com vistas a manter o status quo}

No intuito de desmistificar o embuste presente nas ditas "democracias" capitalistas, Žižek (2008) esclarece a distorção que se dá ao atribuir pesos invertidos a diferentes formas de violência:

Falamos aqui da violência inerente em um sistema: não apenas a violência física direta, mas também as formas mais súbitas de coerção que sustentam a relação de dominação e exploração, incluindo a ameaça de violência [...]. Opondo todas as formas de violência, da direta, violência física (assassinatos em massa, terrorismo) até a violência ideológica (racismo, incitamento, discriminação sexual), essas parecem ser a principal preocupação da tolerante atitude liberal que hoje predomina. Não há algo de suspeito, de fato sintomático, a respeito desse foco na violência subjetiva? [...]. Isso não tentaria desesperadamente distrair nossa atenção do locus do problema, ao obliterar a visão de outras formas de violência, e então, ativamente participar delas? (ŽIŽEK, 2008, p. 9-11, tradução e grifos meus).

O discurso midiático que enfatiza a "violência subjetiva" [aquela impetrada por um sujeito (ŽIŽEK, 2008)], na verdade, salienta a alienação de que fazemos parte. A dispersão das manifestações de 2013 se baseou no medo das formas subjetivas de violência contra o sistema, reforçada pela resposta criminalizadora do Estado, ou seja, pela força policial. Não se pôde concretizar, portanto, uma passagem da indignação coletiva, para uma verdadeira revolução transformadora da ordem social e da violência de Estado que a sustenta. (HARVEY et al., 2012). 
O élan de indignação no Brasil rapidamente arrefeceu ao invés de produzir maiores transformações revolucionárias. Vários setores da sociedade passaram a fortalecer um discurso discriminatório motor de uma espécie de "pensamento mágico" (FREUD, 1913/1996), responsável por trazer pseudo-respostas para questões complexas. O resultado desse ressurgimento da atuação política pela juventude acabou desembocando em uma crise em que o outro, cujos interesses são diferentes, é um estranho a ser eliminado. Conforme se lê em Žižek (2008), a respeito da invisibilidade do próximo:

Um dos significados da alienação é que a distância é tecida no cerne da textura social da vida cotidiana. Mesmo se eu vivo lado a lado com outros, em meu estado normal eu os ignoro. Eu sou permitido a não chegar tão perto dos outros. Eu me movo num espaço social em que interajo com outros de acordo com certas regras "mecânicas" externas, sem partilhar do mundo próprio deles. Talvez a lição a ser aprendida é que algumas vezes uma dose de alienação é indispensável para a coexistência pacífica. Algumas vezes a alienação não é um problema mas uma solução. (ŽIŽEK, 2008, p. 59, tradução minha).

Nesse ponto, é preciso levar em conta o sarcasmo do autor, já que o conjunto de seu pensamento combate a violência perpetuada pelos interesses capitalísticos, sobretudo, quando se ignora e subjuga a existência (e o sofrimento) alheios.

Ignorar essa forma de violência alienatória é típica do comodismo e da indiferença quanto às questões políticas e econômicas que determinam um jogo social totalmente desigual. Ora, é necessário diferenciar questões estruturantes relacionadas à ordem simbólica, em que certo nível de desconhecimento, ou melhor, de não saber e de não conviver, fazem parte do que é possível e suportável à vida, como definiu Freud (1929/1996) no seu texto magistral sobre o mal-estar na cultura, daquelas de ordem política, em que a consciência crítica teria um papel crucial. Ora, além da alienação objetiva do capitalismo (ŽIŽEK, 2008), existe uma renúncia pulsional necessária dada pela vida em cultura. (FREUD, 1929/1996).

Essa indiferença para com o outro aparece na anuência com condições de vida desumanas, tomadas como supostamente imutáveis, como a divisão social de classes em que a maior parte da população mundial vive sob condições precárias e "inferiorizadas". O resultado dessa equação é que o indivíduo comum acaba se alienando, por não se sentir suficientemente potente para 
transformar a realidade diante do imperativo de gozo a que a cultura o submete: "consuma ou não será ninguém". A alienação que invisibiliza o outro tem suas raízes nos interesses individuais, que devem sempre estar em primeiro lugar. Essas condições estabelecidas pela lógica do capital são somadas à intolerância ao próximo tomado como (in)diferente, sobretudo, quando se finge tolerar o outro, ou quando se criam ilusões defensivas de que se aceita a diferença sem preconceitos. Contudo, essa forma de violência dissimulada é demonstrada pela arrogância e falsa superioridade na atitude de "ajudar ao próximo" tomando-o como incapaz, insuficiente e inferior.

\section{A indiferença dos mortos-vivos como salvaguarda da alienação}

A juventude que se autoafirmava "apolítica" e que depois surgiu nas ruas com a fúria da indignação é aqui identificada como os "mortos-vivos" do consumo. Tomando como referência o filme de George Romero (1968), "The night of living death", evocamos a cena em que uma infinidade de zumbis ressurge da tumba e ataca as pessoas num shopping center americano. A interpretação desse cult do cinema é de que todos nós seríamos mortos-vivos, amalgamados aos pequenos ganhos do consumo parcial, em estado de morte psíquica via alienação. "Mortos-vivos" do terceiro milênio, estaríamos desprovidos de ideologias de contracultura devido à queda dos grandes metarrelatos (LYOTARD, 1979/2004), apegados à fantasia de consumo pleno. A condição revolucionária, nesse caso, só poderia advir na pele de zumbis, configurados como psiquicamente mortos, sem potência para a reação política, que atemorizam nossos desejos, como na alegoria do Thriller de Michael Jackson.

Em oposição ao predomínio imaginário da estética dos shoppings centers, Žižek (2011a) cita Badiou, relembrando que: “[...] as favelas [são] um dos poucos lugares eventuais autênticos na sociedade, literalmente daqueles que são "parte alguma", desenraizados e despossuídos, que não têm nada a perder, a não ser os grilhões". (ŽIŽEK, 2011a, p. 420). A ação dessas populações alijadas se funda precariamente, por um lado, na contraviolência dos arrastões e na autoridade dos líderes do tráfico e, por outro, na participação ainda incipiente em manifestações de massa. Nesse sentido, chamou atenção em 2014, o "rolezinho" feito por jovens de comunidades carentes que praticamente levaram a classe média e alta brasileiras ao pânico, quando passaram a se divertir em bando nos shoppings de São Paulo e do Rio de Janeiro. Não seria a impertinência dos jovens que praticaram os "rolezinhos" uma forma de romper com esses grilhões da 
violência capitalista? Com efeito, ao longo dos últimos anos, surgiram formas criativas de oposição ao poder hegemônico, desde debates em redes sociais até, mais recentemente, as ocupações estudantis das escolas públicas.

A transformação dos aparentemente "mortos-vivos", alienados pelo consumo e pelo desinteresse a respeito de política, em "não-mortos", insurgentes, rumou por diferentes caminhos. Aos blackblockers e participantes de ocupações foram destinadas as represálias policiais. Os "não-mortos" identificados com a tradição, adveio a proteção da Polícia Militar, que inclusive posava em fotos com os manifestantes. Afinal, o brilho das câmeras da grande mídia, o acesso ao consumo real, ao ensino de alto padrão, aos altos postos de poder, restaria apenas aos liberais comunistas ${ }^{5}$ e seus clãs de bajuladores. Já aos não-mortos do consumo falho, restaria voltar à condição de "mortos-vivos", já que apenas poderiam usufruir das benesses do capital através de uma tela: a diversão via entertainment, seguindo Adorno (1932/2002) em sua crítica à indústria cultural.

A negação da política se daria na recusa da realidade histórica, prioritariamente alicerçada no apelo estético, na ilusória cruzada anticorrupção e em manifestações violentas pouco efetivas na transformação do sistema político, econômico e social. Ao invés do pensamento crítico, conforme apresentado pelos atores das ocupações, a juventude hipermoderna costuma materializar sua rebeldia no uso de roupas, na recusa ao trabalho e ao estudo, nas adicções e festas de vários dias seguidos, no gozo com o luxo dos acessos aos esportes radicais, etc., etc., enfim, na ignorância completa dos fatos históricos e políticos.

Essa forma de alienação pelo prazer, acampada por uma parte da juventude que se diz orgulhosamente apolítica, pode ser considerada como certa conformação com um laço social perverso, sobretudo em jovens das elites, que supostamente teriam acesso à informação de qualidade. Isso seria sintetizado na gramática: "Eu sei que usufruo de condições econômicas absurdamente abastadas diante da maioria, mas mesmo assim, finjo que sou politizado ao demonstrar minha rebeldia sem causa definida...". Žižek (2008) descreve o desmentido presente na recusa fetichista (fetishist disavowal) da seguinte maneira: "Eu sei, mas eu não quero saber que sei, então eu não sei. Eu sei, mas eu me recuso a assumir completamente as consequências desse conhecimento, então eu posso continuar agindo como se eu não soubesse". (ŽIŽEK, 2012, p. 53, tradução minha).

5 Conforme definido por Žižek (2008), os liberais comunistas são o signo maior da hipocrisia da cultura hipermoderna. Os "liberais comunistas" são os grandes empresários e investidores que, por exemplo, como Bill Gates, justificam o estado de exploração que seu capital lhes permite, ao oferecerem percentagens ínfimas de suas fortunas para caridade. Assim, continuam as práticas neoliberais, fingindo que vão compartilhar dividendos ao darem esmola. 
A figura do liberal comunista, de certa forma, age segundo essa inversão de valores: apesar de saber que obtém somas exorbitantes pelo modo como manipula mais valia, especulação financeira, juros e lucro, o que obviamente sustenta um estado de desigualdade social, continua explorando violentamente o outro, com a desculpa de doar uma pequena parcela de seu lucro às populações miseráveis. Isso ocorre com uma minoria, mas acaba se alastrando como modelo a ser seguido, dada a identificação narcísica com um ideal opressor. É como se fosse: "eu sei que deveria dividir bens, primando pela liberdade, igualdade e fraternidade, mas mesmo assim eu quero ter muito mais do que os outros". Ou ainda: "Eu sei que os comunistas que defendem ideais igualitários estão certos, mas mesmo assim quero ser um liberal desigual, acima da grande maioria". No entanto, se, de um lado, há um laço perverso que constitui a cultura capitalista, de outro, há também a chance de se fazer permeável pela angústia, quebrando os estereótipos do cotidiano cristalizado no consumo e fetichização de objetos. É nesse sentido que pensamos a passagem do estado de "mortos-vivos" alienados para o de "não-mortos" insurgentes, na medida em que se busca retomar a roda da história para dela fazer parte.

A constatação da existência da produção de uma juventude de zumbis apolíticos foi contraposta pela vitalidade dos recentes movimentos insurgentes. Desde a Primavera Árabe, proliferou-se uma onda de esperança cruzando Europa e Américas (ŽIŽEK, 2012; HARVEY et al., 2012) em que a motivação política apareceu revigorada por formas de resistência identitária das minorias (negros, mulheres, diversidade sexual, estudantes secundaristas). Nesse sentido, vimos o esboço de transição de uma subjetividade outrora dita apolítica, para certa politização da vida, ressaltando a passagem de "mortos-vivos" (living dead) a "não-mortos" (undead), de apáticos a ativos. Aproprio-me das duas formas do termo "mortos-vivos" em inglês, artificialmente distinguindo-as por uma tradução literal. Living-dead seriam os que vivem mortos, ou seja, os psiquicamente mortos, alienados pelo consumo, apolíticos. Já os undead seriam os "não-mortos", ou "não mais mortos", sobreviventes da farsa que ressurgem do fosso da alienação para manifestar sua indignação e produzir atos insurgentes, quiçá, revolucionários.

As manifestações públicas que ocorreram em junho de 2013 no Brasil, atingiram todas as classes sociais e se alastraram por praticamente todas as cidades brasileiras. No entanto, seu desfecho foi caracterizado pelo esvaziamento das pessoas comuns e o recrudescimento de atos violentos de blackblocs e mascarados. Essa agressividade orquestrada coletivamente por grupos minoritários seria mesmo o ato político inescapável para a saída de um estado catatônico de alienação política? E as manifestações atuais das ocupações, como pensar a oposição entre os jovens que reivindicam "intervenção militar", de um lado, 
daqueles que ocuparam as escolas públicas de todo país em 2016, reivindicando seus direitos, e de outro? O que estaria em jogo em termos psíquicos, quando levamos em consideração os efeitos identificatórios dados pelo inconsciente coletivo? Em certa medida, as "soluções" encontradas pela população parecem se pautar, ao menos em parte, de ambos os lados, por uma espécie de "pensamento mágico", por vezes, com tendências violentas.

\section{Pensamento mágico, indignação e violência reativa}

A posição subjetiva contemporânea, narcísica e individualista (BIRMAN, 1998/1999; 2012) ainda aparece inflacionada em relação ao espaço de compromisso ético-político pelos modos de reivindicação pública. Seria possível construir uma autocrítica a respeito da ambivalência de práticas que oscilam entre os extremos do consumo compulsivo e da indignação revoltosa? Em que medida referências mágicas e onipotentes sustentam a eclosão da violência presente em manifestações juvenis de resistência? Embora sejam almejadas "mudanças" pela sociedade como um todo, a fragmentação política reitera a falta de coesão entre diferentes grupos diante da crise econômica atual. De playboys filhinhos de papai a yuppies explorados pelas grandes corporações, de professores desvalorizados a estudantes sem preparo, de negros a brancos, de machistas a feministas, do proletariado ao "precariado", de socialites a intelectuais, de ricos a pobres, a onda de manifestações que varreu o mundo e se instalou com força criativa no Brasil, atestou a revivescência da participação na arena política. No entanto, as manifestações se esvaziam quando se instalam os focos de violência, revidados pela violência desproporcional da Polícia e do Estado.

Como exemplo nos blackblocs em 2013, nos professores grevistas em 2015, nos que se posicionaram contra o "golpe jurídico parlamentar", nos servidores e aposentados sem salário que atacaram recentemente a Assembleia Legislativa do Estado do Rio de Janeiro, e, também, em estudantes que ocuparam escolas públicas em 2015-2016, a resposta da violência de Estado sempre foi implacável. Mas a população brasileira ainda se apresenta de forma muito conservadora. Esses sujeitos, identificados com o discurso das mass medias, também parecem tomados por um "pensamento mágico" justiceiro de que eliminar um inimigo único em comum seria a solução para a todos os problemas, condensados sob o mote da corrupção de um único partido. No livro The year of dreaming dangerously [O ano em que sonhamos perigosamente], Žižek (2012) já alertara contra a falácia de manifestações pouco articuladas diante do capitalismo financeiro selvagem: 
[...] deveríamos rejeitar a crítica simplista do "capitalismo financeiro" como se houvesse outra forma "mais justa" de capitalismo. Mas nós deveríamos também evitar a tentação de simplesmente admirar a beleza sublime dos levantes destinados ao fracasso. [...]. Que nova ordem positiva deveria substituir a antiga, uma vez que o sublime entusiasmo diminuiu? É aqui que encontramos a fraqueza fatal dos atuais protestos. Eles expressam uma raiva autêntica que permanece incapaz de se transformar até mesmo em um mínimo programa positivo para mudança sócio-política. Eles expressam o espírito de revolta sem revolução. (ŽIŽEK, 2012, p.78, tradução e grifos meus).

Boa parte da população que participou das mais diferentes manifestações de rua parecia estar lutando contra um inimigo difuso - "o governo" em geral - ou ainda, contra um inimigo específico, com base numa raivosa alucinose coletiva, ao se engajarem a partir de uma identificação histérica com a massa, conforme descreveu Freud (1921).

As cenas de violência televisionadas em 2013 de jovens atacando instituições privadas e órgãos públicos (erroneamente identificados como "símbolos do governo") ganharam a cena, desfocando os esforços rumo a uma conscientização coletiva. O resultado foi uma violência sem propósito específico, movida por uma minoria de jovens, que passou a ser acossada e controlada por forças policiais. Contudo, nem blackblocs, nem o Movimento Ocupa, nem importante Black lives matter americano têm conseguido abalar o cerne do poder do Capital. O recrudescimento de políticas autoritárias mesmo assim vem se fortalecendo. Enfim, como agir pacificamente diante da feroz resposta da violência de Estado?

Conforme Marianne LeNabat (2012), a questão não é apenas definir se o uso da violência é necessário ou não, ou ainda, se existe ou não revolução sem violência. A autora pondera que, fundamentalmente, o uso ou não da violência depende de um acordo coletivo. A contraviolência dos jovens em relação às insígnias do capital pode ser considerada legítima e justificável, pois são essas mesmas trendmarks que assolam a vida de milhões de trabalhadores mundo afora, explorando seu trabalho ou especulando com somas financeiras exorbitantes. Entretanto, a violência direta contra o capital, à moda dos blackblocs, sem um programa revolucionário coletivamente acordado, acaba sendo ineficaz. A reconfiguração da resistência em 2015 e 2016 com o movimento de ocupação das escolas, por sua vez, parece ter mais força e fôlego revolucionários.

Do ponto de vista cognitivo, poderíamos assemelhar essas estratégias do uso da violência para derrubar o poder de Estado com o período pré-operacional descrito por Jean Piaget (1967), caracterizado pelo predomínio da fantasia, em 
que a ação é determinada pela percepção imediata e não por uma representação simbólica da realidade. A atitude violenta de jovens que têm como prerrogativa a transformação do sistema, leva assim a interpretar a presença do "pensamento mágico" (FREUD, 1913/1996), acoplado a episódios de passagem ao ato violento, como forma de resolução de problemas. Trata-se de um pensamento narcísico onipotente (FREUD, 1914/1996) que, além de não conseguir derrubar o sistema, por desventura o reforça.

Mutatis mutandis, tomamos as análises de Winnicott (1971/1975) sobre a transição da "destruição do objeto" ao "uso do objeto", para pensar na estratégia coletiva de "destruir o objeto" capitalismo. Essa estratégia necessariamente é fadada ao fracasso, pois não se trata de lidar com uma "mãe suficientemente boa", que vai suportar o "ataque inconsciente" do bebê e tentar compreender seus anseios primitivos, buscando provê-lo de seus desejos. A reação do Estado tem sido invariavelmente a punição, ao priorizar o uso da força bruta da polícia e do exército. (COIMBRA, 2001; WILL, 2015). Assim, o exercício político enfrenta uma espécie de "Estado tirânico de base", que usa a força, apoiado por boa parte da sociedade civil, também baseada num "pensamento mágico" punitivista. Ao invés de sustentar a ilusão criativa como matéria-prima de transformação social, o Estado contra-ataca, destrói, neutraliza seus jovens heróis insurgentes em busca de um mundo melhor através da força bruta e da renovação da perseguição jurídico-política, já conhecida de tempos de ditadura militar (1964-1984). Jovens passam a ser fichados, vigiados, perseguidos e punidos de modo "exemplar", massacrados pela Polícia Militar e forças similares sob as lentes sensacionalistas das TVs. Os atos de resistência concreta dos jovens insurgentes são considerados como puro vandalismo ${ }^{7} \mathrm{e}$, desse modo, a força das manifestações foi desqualificada perante a opinião pública. Assim, a indignação que brotou da sociedade brasileira como "não-morta", acaba sempre voltando a um estado "morto-vivo" alienatório.

O combate feito pelos jovens contra a violência sistêmica do capital é escamoteado em função da perseguição às diferentes formas de violência

6 Já que estamos longe de uma social democracia real (vide ARENDT, 1969/2011), sobretudo quando considerados os países emergentes, que não atingiram nem de longe o Well Fare State, mantendo ainda severa divisão social de classes.

7 Um episódio trágico fortaleceu ainda mais a crítica da opinião pública e a violência de Estado contra manifestantes. Tratou-se do homicídio culposo cometido por Fabio Raposo e Caio Silva e Souza, que soltaram um rojão que acabou atingindo o cinegrafista Santiago Ilídio Andrade, vítima de morte encefálica em 10 de fevereiro de 2014. Disponível em: <http://noticias.uol.com. br/cotidiano/ultimas-noticias/2014/02/10/morre-cinegrafista-da-band-atingido-por-explosivo-em-protesto-no-rio.htm>. Acesso em: 31 jan. 2015. A partir disso, acirraram-se as medidas de contenção aos movimentos insurgentes no Brasil. 
subjetiva, cometida por sujeitos isolados, portanto, mais fáceis de capturar e neutralizar. Assim, os movimentos sociais são solapados pelo Estado, imbuído de sua violência objetiva, que aos poucos impede e mina o livre fluxo das atividades reivindicatórias. Na medida em que a mídia e o Estado amedrontam a população, expondo a fragilidade dos sujeitos que "optam" pela violência direta, criminaliza-se os jovens e faz a maioria da população retornar à "matriz/matrix" do trabalho alienado, na condição de zumbis mortos em vida. Assim, volta-se a sustentar a "farsa" capitalista (ŽIŽEK, 2011b) de uma existência voltada para a sobrevivência fixado no consumo banal.

Como afirmou Hannah Arendt (1969/2011): "Poder e violência são opostos; onde um domina absolutamente, o outro está ausente. A violência aparece onde o poder está em risco, mas, deixada a seu próprio curso, conduz à desaparição do poder". (ARENDT, 1969/2011, p. 73). Nesse sentido, o recurso ao ato violento (BALIER, 1988) nos jovens que tentam "destruir" o sistema, parece uma alternativa fraca contra o impasse de transformar as práticas capitalistas hegemônicas. Se poder e violência são opostos (ARENDT, 1969/2011, p. 73), a violência incipiente dos manifestantes diante da violência de Estado permite que o poder popular se evanesça, já que o poderio bélico do governo é totalmente desproporcional diante de demandas ainda não articuladas nas massas. Apesar da indignação disseminada por toda a sociedade, o uso da passagem ao ato violento acaba por arrefecer a potência dos movimentos, destituindo o próprio poder que lhe é intrínseco. De lá para cá, os jovens vêm sendo capazes de conquistar novas estratégias de forma mais inteligente, sobretudo quando tomam posse, reivindicam pautas específicas, ocupam e cuidam de SUAS escolas.

A violência advinda da rebeldia jovem, quando não articulada a uma união e decisão coletiva forte, acaba por diminuir o poder revolucionário, adquirindo uma visada delirante, numa espécie de agressividade arrogante (BION, 1957/1994) com explosões mortíferas fundadas num curto-circuito pulsional. (LACAN, 1950). Em certa monta, a violência, mesmo que represente um recurso passível de justificativa, costuma se pautar na onipotência infantil. (FREUD, 1895/1996; OGDEN, 2007).

De fato, a contraviolência cometida por manifestantes revoltosos daria o alimento necessário à reação da força de estado, desviando o foco da pertinente crítica ao modus operandi sistêmico. A violência subjetiva, visível, situável como responsabilidade de um único sujeito ou de um grupo, por sua vez, permite a culpabilização de agentes isolados. Segundo Žižek (2008), a violência subjetiva é apenas a mais visivel [...] (ŽIŽEK, 2008, p. 11), cometida por sujeitos indignados, que embora possam ter razão, acabam por retroalimentar a violência de Estado, e fornecer a justificativa para o uso de aparatos de segurança com vistas à repressão social. 
Em paralelo, a classe média, que pretende manter seus privilégios sem levar em consideração as formas brutas de opressão, é cooptada por um discurso raso em que todo sujeito que comete uma violência (subjetiva) perde a razão. Mas, a questão principal, na realidade, não é se o uso proposital da violência pode ou não levar a uma revolução justa e verdadeira. Conforme Le Nabat (2012), deve ser criticada a falta de acordos coletivos e de sustentação popular para a ação de jovens "revolucionários". Ora, a Revolução Francesa foi extremamente violenta, mas produziu uma nova ordem política, menos injusta, pois não se tratava de um simples levante de indignação, mas de uma revolução amplamente encampada pela sociedade civil historicamente oprimida.

Retomando a premissa winnicotianna de que o bebê precisa "destruir o objeto" para dele poder usufruir no futuro, já que a mãe suficientemente boa sobrevive à sua destruição (WINNICOTT, 1971/1975), é necessário reconhecer a função criativa de certa destrutividade no estabelecimento das fronteiras entre o eu e o outro. Todavia, no plano do inconsciente coletivo, não basta a idealização de um mundo melhor fundada no "pensamento mágico" e na "passagem ao ato violento" para se produzir mudanças, ainda que as utopias sejam necessárias. A crítica severa à divisão de classes preconizada por grupos insurgentes não deve ser substituída por atos violentos com a crença de que o capitalismo financeiro possa explodir, ao se quebrar agências bancárias ou com a simples ocupação das ruas e das escolas. Isso seria subestimar as estruturas de poder global, restando tais tentativas no plano da ilusão onipotente. É preciso mais clareza sobre o que se almeja alcançar e estruturar novas estratégias psíquicas para revolucionar a realidade.

Contraditoriamente, a agressividade produtora das revoltas talvez seja condição sine qua non no plano revolucionário. Sem prever solução, indagaríamos: até que ponto pode ser tolerada ou criminalizada a contra violência eclodida nas manifestações de rua em relação à violência instituída de Estado, se, continuamente, crianças e jovens são tornadas invisíveis e assassinadas nas comunidades carentes de todo Brasil? Na introdução do livro Violence, Žižek (2008) se inspira numa fala de Lenin de que a melhor arma para transformar a realidade seria o estudo sistemático das condições que nos oprimem, pela invocação a se aprender continuamente. Aposta, portanto, na retirada para o pensamento crítico, ao invés da atuação com base no "pensamento mágico" que aqui denunciamos. Em momentos de impasse, o mais recomendado seria a atitude de estudar, raciocinar, dialogar e negociar demandas coletivas como saída para o estado de alienação e de dominação em que se encontram os "mortos-vivos" contemporâneos. Nesse sentido, Žižek (2011a) afirma que toda a nossa vida social é determinada por esses mecanismos reificados pelo mercado onde 
“[...] ninguém é responsável, todos estão presos na ânsia objetivada de competir, lucrar e de manter o fluxo de circulação de capital". (ŽIŽEK, 2011a, p. 448).

De acordo com Freud (1929/1996), o próprio ser humano, "inteligentemente", produz desvios aos desígnios da natureza, tentando livrar-se da sua fragilidade e desamparo, com a meta de elevação de seu ser a uma condição divina. Por que não pensar que os espaços criados para o "consumo", que iludem o sujeito com a divindade dos objetos, como shopping centers, casas de shows, lojas, estádios, supermercados, etc., concebidos como "espaços" de entretenimento, não seriam justamente aquilo que mais aprisiona o usufruto do tempo subjetivo no engajamento político? Usando as palavras de Freud, a força esmagadoramente superior da natureza, atualmente encampada pelo deus capital, não seria a pior forma de violência cuja maior atrocidade seria sustentar o prenúncio de Sade: "deixai fluir vossas paixões e sereis salvos!”. (FREUD, 1929/1996, p. 61)?

Parafraseando Freud, Žižek (2011b) condena a nova religião do consumo, atualizando o décimo mandamento referente ao efeito da economia de mercado: "[...] libertarás tuas pulsões e buscarás um gozo sem limites! O que resultaria na destruição da economia do desejo e substituição pela economia do gozo". (ŽIŽEK, 2011b, p. 66). Os ensinamentos de Freud em O futuro de uma ilusão (1927) apontam que nossa inserção na cultura se dá pela estruturação do superego via internalização de algumas coerções externas, sobretudo as crenças religiosas, que exigem uma renúncia pulsional severa. Afinal, a religião é baseada por excelência na exploração do "pensamento mágico" e em sua contrapartida de medo e temor. Mas, o advento da hipermodernidade, ao contrário da repressão moderna, aponta que renunciar às interdições e viver uma vida em que tudo é possível, passa a ser o ideal de gozo em que as políticas do desejo e o desejo pelo trabalho político não têm lugar. Mas, ficarmos relegados à nossa própria natureza erótica mesquinha não seria o fim da civilização?

Ficar anestesiado no registro do gozo pelo consumo de objetos e corpos, ou seja, numa lógica fetichizada que apenas exacerba nossa natureza pulsional, certamente torna menos eficiente a ação política concatenada sob uma ótica coletiva, logo, empobrece a cultura. A passagem ao ato violento nas manifestações disseminadas hodiernamente pelo mundo afora, normalmente, não levou a grandes resultados revolucionários, posto que a violência de Estado predomina. Como então constituir maneiras mais duradouras, inteligentes e eficientes para romper com o estado de zumbis apolíticos da maioria dos sujeitos alienados pelo consumo? Em resumo, ao analisar a relações entre violência e poder, Arendt (1969/2011) propôs: 
[...] os seres humanos são responsáveis pelo mundo em que vivem, e de fato eles são livres para refazê-lo como quiserem. [...] "a nossa liberdade de agir pertence não a nossa capacidade individual de fazer exatamente o que quisermos, mas sim para as maneiras pelas quais podemos nos envolver com outros atores livres, em criativos empreendimentos coletivos para moldar ou reformular nosso mundo, assim como vemos no caso de movimentos políticos recentes. A base da eficácia de tais movimentos em sua luta contra os sistemas arbitrários de dominação que eles enfrentam é a sua terra (natalidade) em ação coletiva. (ARENDT, 1969/2011, p. 83, citado por LENABAT, 2012).

Assim, concluímos que os jovens, em seus movimentos por mudança, isto é, em suas tentativas de forjar uma nova história, agirão sempre que, quando em condições de restrição severa, perceberem-se explorados e indignados. Contudo, as condições de possibilidade de que a resistência ao poder vigente leve a uma revolução, ao contrário do apelo delirante à violência bruta, depende de que possamos "aprender, aprender e aprender", dialogando coletivamente, de modo que a fonte de eficácia da mobilização em um pensamento crítico, e não "mágico", seja a base de sua liberdade.

\section{REFERÊNCIAS}

ADORNO, T. Indústria cultural e sociedade. São Paulo: Paz e Terra, 2002.

ARENDT, H. (1969). Sobre a violência. Rio de Janeiro: José Olympio, 2011.

BALIER, C. Psychanalyse des comportements violents. Paris: PUF, 1988.

BION, W. R. (1957). Sobre a arrogância. In: Estudos psicanalíticos revisitados - Second Thoughts. Rio de Janeiro: Imago, 1994.

BIRMAN, J. (1998). Mal-estar na atualidade. Rio de Janeiro: Civilização Brasileira, 1999.

BIRMAN, J. O sujeito contemporâneo. Rio de Janeiro: Civilização Brasileira, 2012.

COIMBRA, C. Operação Rio: o mito das classes perigosas. Niterói: Intertexto, 2001.

DUFOUR, D. R. (2009). A cidade perversa: liberalismo e pornografia. Rio de Janeiro: Civilização Brasileira, 2013. 
ARREGUY, M. E. De "mortos-vivos" a "não-mortos": pensamento mágico, violência...

DUFOUR, D. R. O divino mercado. Cadernos de Psicanálise - Círculo Psicanalítico do Rio de Janeiro, ano 32, n. 23, p. 55-66, 2010.

FOUCAULT, M. Em defesa da sociedade: Curso no Collège de France (1975-1976). São Paulo: Martins Fontes, 2000.

FREUD, S. (1895). Projeto para uma psicologia científica. In: FREUD, S. Edição Standard Brasileira das Obras Psicológicas Completas de Sigmund Freud [ESB]. Rio de Janeiro: Imago, 1996. v. I.

FREUD, S. (1905). Três ensaios sobre a teoria da sexualidade. In: FREUD, S. ESB. Rio de Janeiro: Imago, 1996a. v. VII.

FREUD, S. (1913). Animismo, magia e onipotência de pensamentos. In: FREUD, S. Totem e tabu - ESB. Rio de Janeiro: Imago, 1996b. v. XIII.

FREUD, S. (1914). À guisa de introdução ao narcisismo. In: FREUD, S. Escritos sobre a Psicologia do Inconsciente - Obras Psicológicas de Sigmund Freud. Rio de Janeiro: Imago, 2004. v. 1.

FREUD, S. (1921). Psicologia de Grupo e análise do Ego. In: FREUD, S. ESB. Rio de Janeiro: Imago, 1996. v. XVIII.

FREUD, S. (1927). O futuro de uma ilusão. In: FREUD, S. ESB. Rio de Janeiro: Imago, 1996. v. XXI.

FREUD, S. (1929). O mal-estar na civilização. In: FREUD, S. ESB. Rio de Janeiro: Imago, 1996. v. XXI.

HARVEY, D. et al. Occupy: movimentos de protestos que tomaram as ruas. São Paulo: Boitempo - Carta Maior, 2012.

LACAN, J. (1950). Introduction théorique aux fonctions de la psychanalyse en criminologie. In: LACAN, J. Écrits. Paris: Seuil, 1966. p. 125-149.

LACAN, J. (1972-3). Encore. Le séminaire de Jacques Lacan, Livre XX. Paris: Seuil, 1975.

LYOTARD, J. F. (1979). A condição pós-moderna. Rio de Janeiro: José Olympio, 2004.

LE NABAT, M. On non-violence: An Arendtian perspective on recent political movements. International Critical Thought, v. 2, n. 4, p. 456-471, Dec. 2012.

OGDEN, T. H. On Talking-as-dreaming. Inter. Journal of Psychoanalysis, v. 88, p. 575-89, 2007.

PIAGET, J. (1967). Seis estudos de psicologia. Rio de Janeiro: Forense-Universitária, 1987.

WILL, S. V. Vigiar, Punir, Educar e Matar: Discursos de disciplinamento, controle e extermínio da população preta e pobre do Rio de Janeiro. Tese (Doutorado) - Programa de Pós-Graduação em Educação, Universidade Federal Fluminense, Niterói, 2015. 
WINNICOTT, D. W. (1971). O brincar e a realidade. Rio de Janeiro: Imago, 1975.

ŽIŽEK, S. Violence: Six sideways reflections. New York: Picador, 2008.

ŽIŽEK, S. Em defesa das causas perdidas. São Paulo: Boitempo, 2011a. Disponível em: <http://pt.scribd.com/doc/192653442/ZIZEK-Slavoj-Em-Defesa-Das-Causas-Perdidas-Retail $>$.

ŽIŽEK, S. (2009). Primeiro como tragédia depois como farsa. São Paulo: Boitempo, $2011 b$.

ŽIŽEK, S. The year of dreaming dangerously. London / New York: Verso, 2012.

Texto recebido em 23 de dezembro de 2016.

Texto aprovado em 03 de janeiro de 2017. 
